\title{
Prevalence of anemia in children aged 6 months to 15 years: a hospital based study
}

\author{
Sharma Anna ${ }^{1}$, Giri Abhishek ${ }^{1}$, Pudasaini Sujata ${ }^{2}$ \\ ${ }^{I}$ Department of Pediatrics, Nepal Medical College and Teaching Hospital, Kathmandu, Nepal \\ ${ }^{2}$ Department of Pathology, Nepal Medical College and Teaching Hospital, Kathmandu, Nepal
}

\section{Keywords:}

Anemia;

Enteric fever;

Nutritional status;

Pneumonia

\begin{abstract}
Background: Anemia is a common problem in small children and in adolescents in Nepal. We conducted this study to estimate the prevalence of anemia in hospitalized children in our setup.

Materials and Methods: Children aged 6 months to 15 years with hemoglobin $<11 \mathrm{gm} / \mathrm{dl}$ were enrolled. Clinical details of patients including the demographic characteristics, anthropometry, final diagnosis and laboratory results were recorded and retrieved for analysis.

Result: Prevalence of anemia was 42.3\%. Mean hemoglobin was $9.51 \mathrm{gm} / \mathrm{dl}$. Anemia was more common in children more than five years (53.3\%). Seventy Three percent had mild, 20.9\% had moderate and 5.7\% had severe anemia. Grade I malnutrition was seen in $24.8 \%$, Grade II in $20.9 \%$ and grade III in $5.7 \%$. Pneumonia was seen more commonly in children with mild and moderate anemia.
\end{abstract}

Conclusion: Anemia is a common problem in children and may be associated with respiratory infections.

\section{Correspondence:}

Dr. Anna Sharma, MD

Asst. Professor, Department. of Pediatrics

Nepal Medical College and Teaching Hospital, Kathmandu, Nepal ORCID ID: 0000-0002-3191-3000

Email:anyasharma@hotmail.com

Received : March 16th, 2017; Accepted : July 7th, 2017; Published : September 1, 2017

Citation: Sharma A, Giri A, Pudasaini S. Prevalence of anemia in children aged 6 months to 15 years: a hospital based study. J Pathol Nep. 2017;7:1168-71. doi: 10.3126/jpn.v7i2.17996

Copyright: This is an open-access article distributed under the terms of the Creative Commons Attribution 4.0 International License, which permits unrestricted use, distribution, and reproduction in any medium, provided the original author and source are credited.

\section{INTRODUCTION}

Anemia is a global public health problem affecting both developing and developed countries. It occurs at all stages of the life cycle, but it is more prevalent in pregnant women and young children. Globally, anemia affects 1.62 billion people, which corresponds to $24.8 \%$ of the population. 1 The highest prevalence is in preschool children (47.4\%) and the lowest is in men (12.7\%). ${ }^{1}$ Anemia is a severe public health problem in Nepal as the studies done previously have shown a high prevalence especially among preschool children and young females. ${ }^{2}$ World Health Organization (WHO) defines anemia according to the hemoglobin threshold in different age group which is as follows: ${ }^{3}$ 
Age

Hemoglobin threshold (gm/dl)

Children (0.5-4.9 yrs)

11.0

Children (5.0- 11.9 yrs)

Children (12-14.9 yrs)

Severity of anemia is classified according to WHO as follows:

Severe anemia

$<7.0 \mathrm{gm} / \mathrm{dl}$

Moderate anemia

$7.0-8.9 \mathrm{gm} / \mathrm{dl}$

Mild anemia

$9.0-10.9 \mathrm{gm} / \mathrm{dl}$

This study was done to know the prevalence of anemia in admitted children in Nepal Medical College and Teaching Hospital which is located in north eastern part of the valley.

\section{MATERIALS AND METHODS}

This was a prospective, descriptive, cross sectional hospitalbased study carried out at Nepal Medical College and Teaching Hospital (NMCTH). All Children aged 6 months to 15 years admitted in the pediatric ward of NMCTH from mid-April 2014 to mid-October 2014 were initially taken for the study. Prior to study, permission was obtained from institutional review board. Verbal consent was taken from parents before enrolling children for the study. Children in whom routine hemogram was not done and whose clinical details were missing were excluded. Parents not giving verbal consent for the participation in the study were excluded. Patient with hemoglobin level less than $11.0 \mathrm{gm} /$ $\mathrm{dl}$ were enrolled. All the required data were collected and were analyzed using Microsoft Excel.

\section{RESULTS}

During the study period a total of 248 patients between 6 months and 15 years of age were admitted in the pediatric ward. Out of these 248 patients $105(42.3 \%)$ had anemia. Among the 105 anemic cases, 51 (48.6\%) were male and $56(51.4 \%)$ female. Thirteen patients $(12.4 \%)$ were between 6 months to 12 months, 36 patients $(343 \%)$ were between 1 year and 5 years and 56 patients $(53.3 \%)$ were in the age group 5 years to 15 years. Among the study population mean hemoglobin was $9.51 \mathrm{gm} / \mathrm{dl}$. Based upon WHO criteria, 77 patients $(73.3 \%)$ had mild, 22 patients $(20.9 \%)$ had moderate and 6 patients $(5.7 \%)$ had severe anemia (fig. 1). According to the Indian Academy of Pediatrics (IAP) classification, 51 cases $(48.6 \%)$ had normal nutritional status. Grade I malnutrition was seen in 26 cases $(24.8 \%)$, Grade II in 22 cases (20.9\%) and grade III in 6 cases (5.7\%). (Table 1).

Acute respiratory tract infection was the most common diagnosis in 33 cases $(31.4 \%)$ children with anemia followed by enteric fever in 18 cases (17.1\%) (fig. 2). Acute gastroenteritis, febrile convulsion, urinary tract infection, tuberculosis were other infectious conditions in these children

Fifty-two children (50.0\%) with moderate anemia and 30 children $(28.6 \%)$ with mild anemia had pneumonia. There were 6 children with severe anemia and all of them were more than 5 years of age. Microcytic hyochromic anemia was seen in four of them and two had normocytic normochromic anemia.

\section{DISCUSSION}

It is estimated that $30 \%$ of the global population suffer from iron deficiency anemia and most of the affected live in developing countries. ${ }^{4}$ Prevalence of anemia in children in our study was $42.3 \%$. Similar study done in one of the hospitals in Kathmandu valley also reported prevalence of anemia in children aged 6 months to 60 months to be $46.0 \%{ }^{5}$ However, community based studies on adolescent girls have reported much higher prevalence of anemia $(60.5 \%$ to $78.3 \%){ }^{6,7}$ In India, various studies have reported prevalence of anemia in less than five years children to be 70 to $80 \% 0^{8-10}$ However, prevalence of anemia in adolescent girls in different geographical areas in India ranged from 40 to $99.9 \% .{ }^{11}$ Studies done in Brazil have also shown higher prevalence $(57.3 \% \text { to } 60.4 \%)^{12,13}$ of anemia in children below five years of age where as prevalence was much lower in western China $(32.7 \%))^{14}$

Most of the children (73.3\%) had mild anemia in our study. Other studies have also reported higher percentage of mild anemia. ${ }^{5-7}$ In our study, almost half of the children with anemia were in various states of malnutrition. Almost one third of the children were suffering from acute lower respiratory tract infections including pneumonia and wheeze associated lower respiratory tract infections. One of the hospital based study done in Pokhara reported low hemoglobin level to be the risk factor for acute lower respiratory tract infections. ${ }^{15}$

Globally, the most significant contributor to the onset of anemia is iron deficiency so that iron deficiency anemia (IDA) and anemia are often used synonymously. Intestinal parasites may be one of the causes of anemia in school going children. A study done in Bangalore, India reported much lower prevalence $(13.6 \%)$ of anemia in school aged children after initiation of deworming and vitamin A

\begin{tabular}{|c|c|c|c|c|}
\hline & Normal & Grade I & Grade II & Grade III \\
\hline $\begin{array}{l}\text { Mild } \\
\text { anemia }\end{array}$ & 39 & 21 & 16 & 1 \\
\hline $\begin{array}{l}\text { Moderate } \\
\text { anemia }\end{array}$ & 9 & 4 & 5 & 4 \\
\hline $\begin{array}{l}\text { Severe } \\
\text { anemia }\end{array}$ & 3 & 1 & 1 & 1 \\
\hline Total & $51(48.6 \%)$ & $26(24.8 \%)$ & $22(20.9 \%)$ & $6(5.7 \%)$ \\
\hline
\end{tabular}




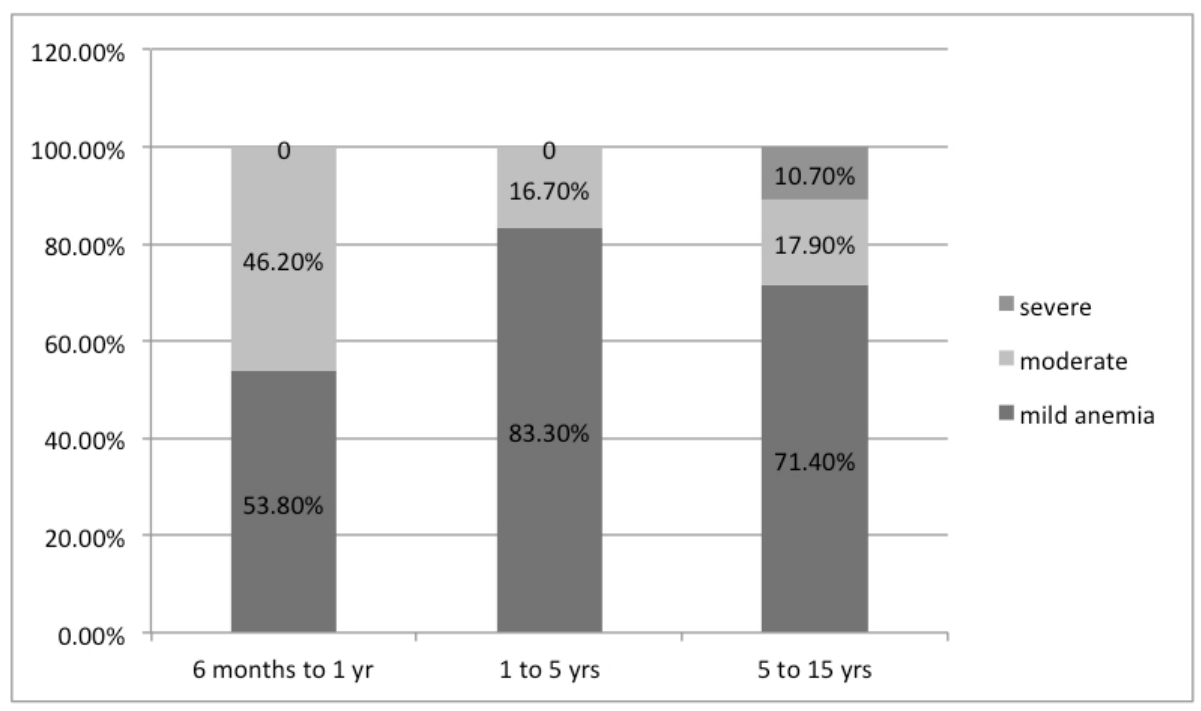

Figure 1: Severity of anemia in different age group

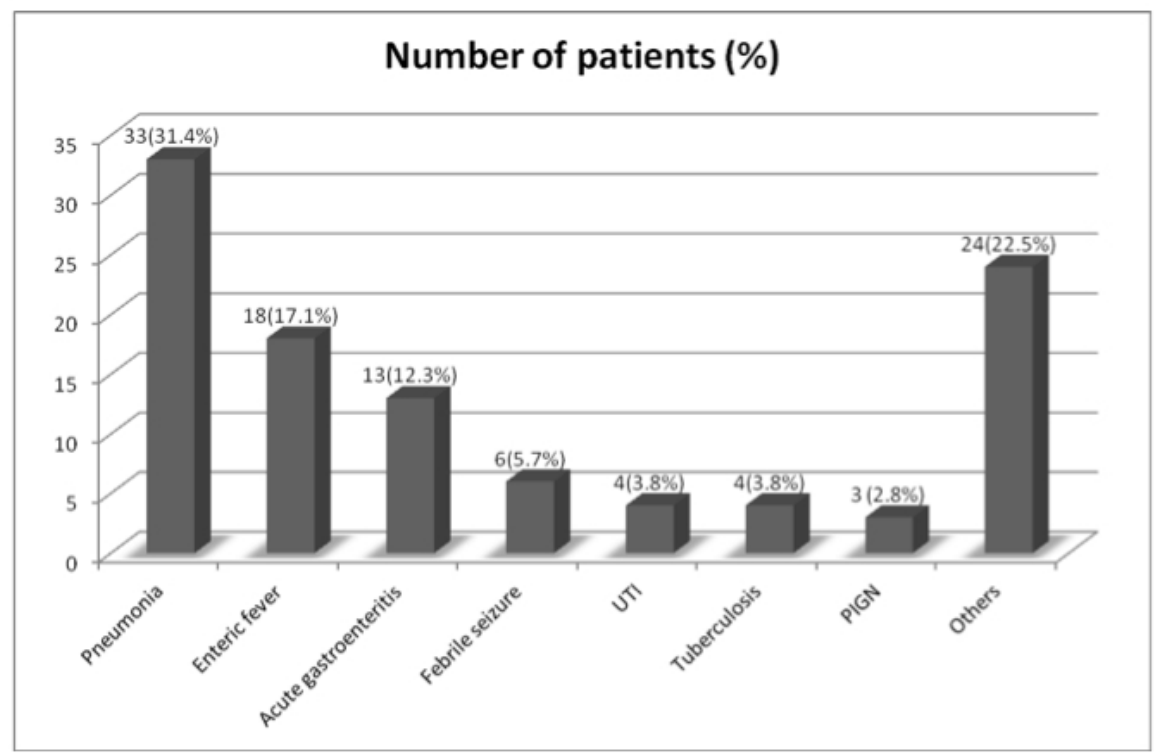

Figure 2: Clinical diagnosis of the patients 'with anemia.

supplementation as school based intervention program. ${ }^{16}$ Anemia in children especially iron deficiency have effects on neurological and intellectual function. These children may have poor attention span and learning difficulties. ${ }^{4}$

Anemia is a common problem in small children as well as in adolescents. It not only affects the growth of the children, but also affects their learning capacity and cognitive behaviour. Malnourished children are more prone to develop anemia and anemia itself may be the risk factor for the development of respiratory infections. Hence, anemia in small children must be prevented by food fortification with iron or as iron supplementation. Mass programs like deworming and vitamin A supplementation must be conducted on a regular basis. Health education should be given to adolescents regarding healthy food habits.

\section{CONCLUSION}

Anemia is a common problem in Nepalese children associated more with respiratory tract infections and malnutrition. Nutritional supplementation, deworming and health education is vital for its prevention.

\section{Conflict of interest: None}

\section{REFERENCES}

1. Benoist B, Mclean E, Egli I, Cogswell M. Worldwide prevalence of anemia 1993-2005: WHO global database on anemia. (Cited17 June 2017). Crossref

2. Ministry of Health Nepal.Nepal micronutrient survey 1998, Kathmandu, Ministry of Health, 1999. (Cited17 June 2017). Crossref

3. Iron deficiency anemia: assessment, prevention and control. A guide for programme managers. Geneva, World Health Organization, 2001 (WHO/NHD/01.3). (Cited17 June 2017). Crossref

4. Bertil G. Diseases of the Blood: The Anemias. Nelson Textbook of 
Pediatrics Vol 2 18th eds. Kleigman RM, Behrman RE, Jenson HB, Stanton BF. Saunders: New Delhi; 2008. p2003-16.

5. Bajracharya BL, Manandhar DS, Baral MR. Hemoglobin status in children in the age group 6 to 60 months. J Nep Med Assoc 2006;45:190-5

6. Tiwari K, Seshadri S. The prevalence of anemia and morbidity profile among school going adolescent girls of urban Kathmandu, Nepal. J Nep Med Assoc 2000;39:319-25.

7. Baral KP, Onta SR. Prevalence of anemia amongst adolescents in Nepal: a community based study in rural and urban areas of Morang district. Nepal Med Coll J 2009;11:179-82. Crossref

8. Awasthi S, Das R, Verma T, Vir S. Anemia and undernutrition among preschool children in Uttar Pradesh, India. Indian Pediatr 2003;40:985-90. Crossref

9. Kotecha PV. Nutritional Anemia in Young Children with Focus on Asia and India. Indian J Community Med 2011;36:8-16. Crossref

10. Sinha N, Deshmukh PR, Garg BS. Epidemiological correlates of nutritional anemia among children (6-35 months) in rural Wardha, Central India. Indian J Med Sci 2008;62:45-54. Crossref
11. Bharati P, Shome S, Chakrabarty S, Bharati S, Pal M. Burden of anemia and its socioeconomic determinants among adolescent girls in India. Food Nutr Bull 2009;30:217-26. Crossref

12. Oliveira CS, Cardoso MA, Araújo TS, Muniz PT. Anemia in children 6 to 59 months of age and associated factors in Jordão, Acre State, Brazil. Cad Saude Publica 2011;27:1008-20. Crossref

13. Neuman NA, Tanaka OY, Szarfarc SC, Guimarães PR, Victora CG. Prevalence and risk factors for anemia in Southern Brazil. Rev Saude Publica 2000;34:56-63. Crossref

14. Zeng LX, Yan H, Chen ZJ, Dang SN, Xie H. Analysis on the prevalence of anemia among children under 3-year-old in 5 provinces in Western China. Zhonghua Liu Xing Bing Xue Za Zhi 2004;25:2258. Crossref

15. Malla T, Pathak OK, Malla KK. Is low hemoglobin level a risk factor for acute lower respiratory tract infection? J Nepal Paediatr Soc 2010;30:1-7

16. Muthayya S, Thankachan P, Zimmermann MB et al. Low anemia prevalence in school-aged children in Bangalore, South India: possible effect of school health initiatives. Eur J Clin Nutr 2007;61:865-9. Crossref 